\title{
Notes on mating behaviour and a possible new host plant for Megacyllene angulata (Fabricius, 1775) (Cerambycidae, Coleoptera)
}

\author{
Francisco Eriberto de Lima Nascimento ${ }^{1,3}$; Diego Matheus de Mello Mendes ${ }^{2,4}$ \& Alberto Moreira da Silva Neto ${ }^{2,5}$ \\ 1 Universidade de São Paulo (USP), Museu de Zoologia (MZUSP). Avenida Nazaré, 481, Ipiranga, CEP 04263-000, São Paulo, SP, Brasil. \\ 2 Instituto Nacional de Pesquisas da Amazônia (INPA), Coordenação de Pesquisas em Entomologia (CPEN), Programa de Pós-Graduação em \\ Entomologia (PPG-ENT). Campus II. Avenida André Araújo, 2.936, Petrópolis, CEP 69067-375, Manaus, AM, Brasil. \\ 3 ORCID: http://orcid.org/0000-0002-5047-8921. E-mail: eribnascimentofl@gmail.com \\ ${ }^{4}$ ORCID: http://orcid.org/0000-0001-5037-9686E-mail: diego.mello.mendes@gmail.com \\ ${ }^{5}$ ORCID: http://orcid.org/0000-0002-4522-3756. E-mail: bio.alberto@gmail.com (corresponding author)
}

\begin{abstract}
The mating behavior of M. angulata (Fabricius, 1775) is described, illustrated and discussed. Additionally, we also comment on the possible new host plant of this species based on two plants (Luehea cymulosa Spruce ex Benth. (Malvaceae) and Doliocarpus dentatus (Aubl.) Standl (Dilleniaceae) on which copulation occurs.
\end{abstract}

Key-Words. Amazon region; Behaviour; Ecology; Longhorned beetle.

\section{INTRODUCTION}

Clytini Mulsant, 1839 is a cosmopolitan tribe composed of 83 genera, among which Megacyllene Casey, 1912 is the eighth most diverse, with 57 species distributed throughout the American continent (Monné, 2018; Tavakilian \& Chevillote, 2018). The South American species were revised by Martins \& Galileo (2011). Few species of the genus occur in the Amazon region. Among these, M. angulata (Fabricius, 1775) is one of the most widely distributed, occurring from Mexico to the Brazilian Amazon (Martins \& Galileo, 2011).

According to Lingafelter et al. (2017), M. angulata has 10-15 mm. These authors stated: "Resembles M. acuta [M. acuta (Germar, 1821)] and has similar habits. It is best distinguished from that species by having darker recumbent pubescence on the elytra and by its central elytral fasciae, which are narrow lines and extend well up the elytral margin in contrast to the irregular shape and short sutural extension of those of M. acuta."

Knowledge about the mating behavior of the vast majority of cerambycids species is still unknown. In most studied species, males recognize females only after contacting them with their antennae (Hanks \& Wang, 2017). In general, both sexes aggregate on the larval host where males typically approach females to copulate, then, males remain paired with female while it searches for oviposition sites (Hanks, 1999). This behavior allows males to mate several times, ensuring paternity of eggs and prevents the female from copulating with other males (Hanks \& Wang, 2017).

Another important aspect is that males of many species have the antennae longer than females (in general, more than twice the body length). According to Hanks et al. (1996), this dimorphic feature has selective advantage, by increasing the rates of female location and by improving their abilities to find the place where females commonly oviposit. According to the same author, the antenna length is also related to the male's behavior, usually more active than females.

Nonetheless, many species of Cerambycidae have relatively short antennae, not exceeding the elytral apices, such as Megacyllene species. The mating behavior of such species also differs drastically from those with long antennae (Ray et al., 2009). Herein we describe, illustrate and discuss the mating behavior of $M$. angulate. Additionally, we also comment on possible new host plant of this species based on two plants (Luehea cymulosa Spruce ex Benth. (Malvaceae) and Doliocarpus dentatus (Aubl.) Standl (Dilleniaceae) on which copulation was observed.

\section{MATERIAL AND METHODS}

The observation occurred on December 15, 2018. The location is a lowland forest glade, on a 
fluvial island between the Solimões and Tefé rivers, Tefé, Amazonas, Brazil (0319'57.6"S, 6441'14.1"W) (Fig. 1). In the glade, part of the vegetation had recently been cut for logging, including trees and vines.

The identification of $M$. angulata was made at LAC (Laboratório de Coleoptera do Museu de Zoologia da Universidade de São Paulo, São Paulo, Brazil) through specialized bibliography and comparison with deposited specimens. The photographs were taken from alive specimens using a Nikon 7100 digital camera, with a $65 \mathrm{~mm}$ Macro lens. The other images were taken with a Leica DFC295 attached at a stereoscopic microscope M205. The illustration was made using the Adobe Illustrator CS6 and Adobe Photoshop CS6. Figure plates were edited with the Adobe Photoshop, free software GIMP 2.10.6 (GNU Image Manipulation Program), and Inkscape 0.48.4. The map was made through ArcMap ESRI software Version 9.3. The distributional data are based on Tavakilian \& Chevillotte (2018) and Monné (2018). The host plants data follows Monné (2001).

\section{RESULTS}

\section{CERAMBYCINAE Latreille, 1802 CLYTINI Mulsant, 1839 Megacyllene Casey, 1912} Megacyllene angulata (Fabricius, 1775) (Fig. 3A-F)

Distribution: Mexico (Chiapas, Veracruz), Guatemala, Nicaragua, Costa Rica, Panama, Venezuela, Colombia, Ecuador, Surinam, Guyana, French Guiana, Brazil (Roraima, Amapá, Amazonas, Pará, Rondônia, Maranhão, Mato Grosso, Mato Grosso do Sul), Peru, Bolivia (Beni, Santa Cruz), Dominica.
Hosts - Alexa leiopetala Sandwith, A. wachenheimii R. Ben. (Papilionaceae), Faramea corymbosa Aublet (Rubiaceae).

\section{Mating behavior (Figs. 2A-D)}

Several specimens of Megacyllene angulata were observed on a single specimen of Doliocarpus dentatus (Aubl.) Standl (Dilleniaceae). The vine was cut, but it was still fixed on the canopy of a large tree of Luehea cymulosa Spruce ex Benth. (Malvaceae). In the cut part of the vines (about 1.5 meters above the ground) there was sap dripping and several male and female specimens of $M$. angulata clustered in this region (Fig. 2A). The specimens showed a repetitive behavior climbing from the cut part to a region 3 meters above the cut and vice-versa. During this movement there were several copulation attempts, in which males frantically pursued females (Fig. 2B). Most of the copulations, when initiated, were interrupted by aggressive behaviors of other males biting especially the pronotum and antennal base of the male specimen in mating (Fig. 2C). Couples, which escaped the attacks, climbed to the upper part of the vine (about 2 meters above the cut) and remained immobile on the region of the vine not directly exposed to sunlight (Fig. 2D).

\section{DISCUSSION}

The species Luehea cymulosa is widely distributed in Amazon region and we believe that it is possibly another host plant of $M$. angulate. Although no hatching of $M$. angulata has been observed, the large number of $M$. angulata mates on a vine attached to L. cymulosa and the Amazonian distribution of this tree underlies this argument.

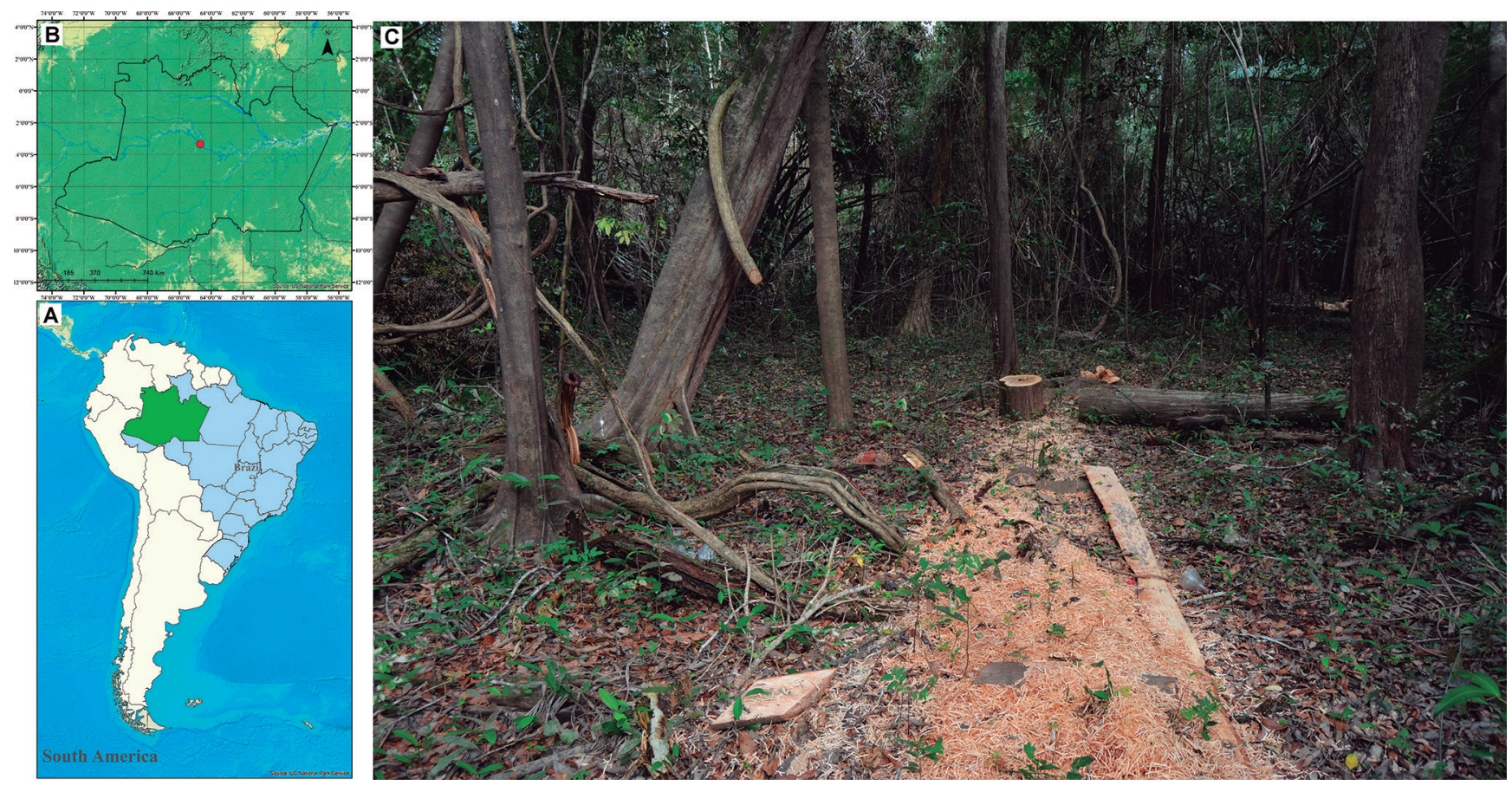

Figure 1. Location where the observations occurred. (A) South American with Amazonia state (Brazil) marked; (B) Amazonia state with the location of observation in Tefé municipality marked (red point); (C) area of observation. 

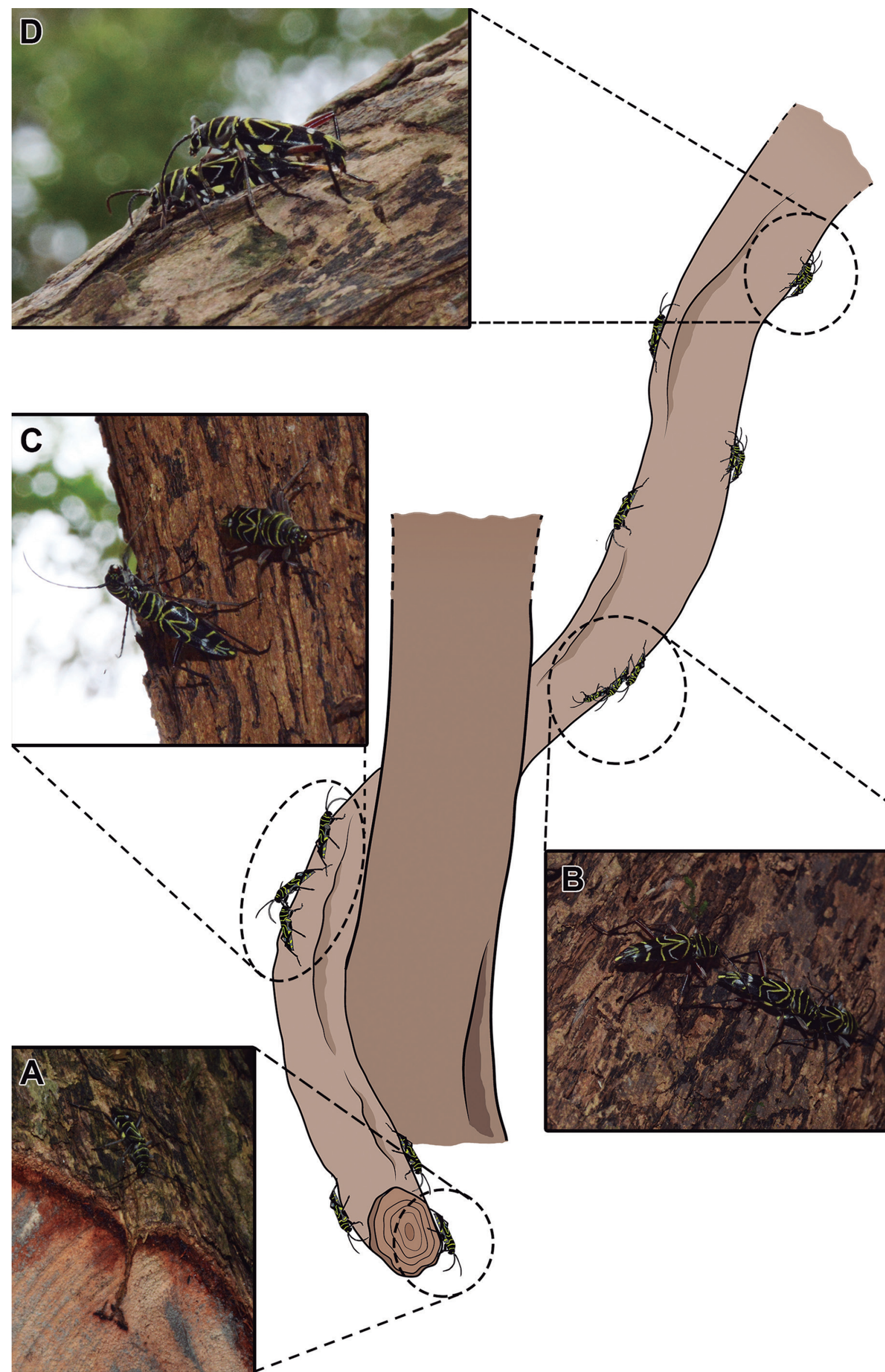

Figure 2. Specimens of Megacyllene angulata performing mating behavior. (A) Male and female specimens clustered in a region of the vine. (B) Males frantically pursued females. (C) Copulations interrupted by aggressive behaviors of other males. (D) Couple in copulation, immobile on the region of the vine not directly exposed to sunlight. 
Megacyllene angulata mating was observed on the vine Doliocarpus dentatus, therefore the vine is also a possible host plant of this beetle, although their distributions do not completely overlap: $D$. dentatus is widely distributed in all regions of Brazil: North (Acre,
Amazonas, Amapá, Pará, Rondônia, Roraima, Tocantins); Northeast (Alagoas, Bahia, Ceará, Maranhão, Paraíba, Pernambuco, Piauí, Rio Grande do Norte, Sergipe); Central-West (Distrito Federal, Goiás, Mato Grosso do Sul, Mato Grosso); Southeast (Espírito Santo, Minas Gerais,
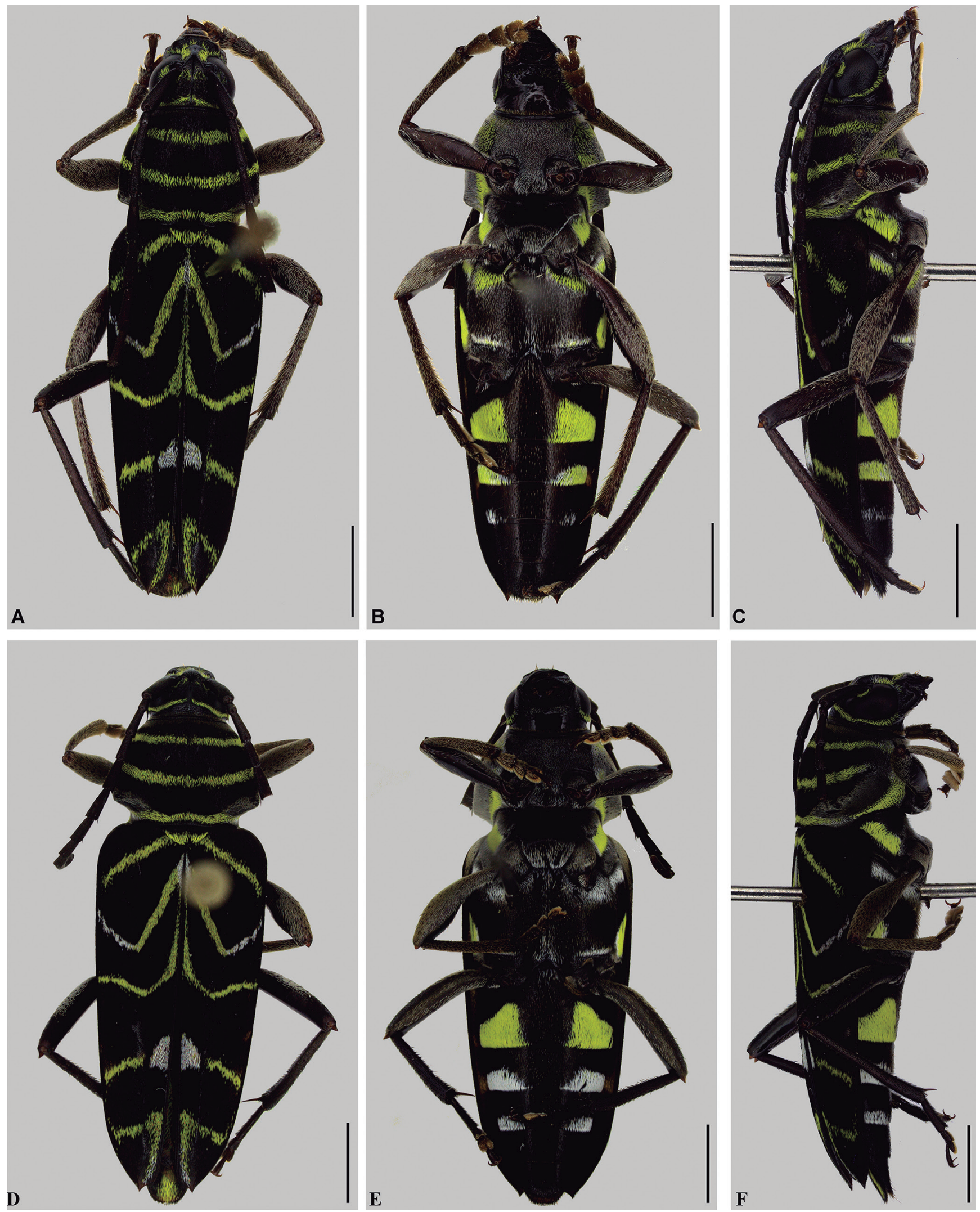

Figure 3. Megacyllene angulata (Fabricius, 1775). (A-C) male. (A) dorsal habitus; (B) ventral habitus; (C) lateral habitus. (D-F) female. (D) dorsal habitus; (E) ventral habitus; (F) lateral habitus. Scale bar $=2 \mathrm{~mm}$. 
Rio de Janeiro, São Paulo) and South (Paraná), Covering all biomes (Amazônia, Caatinga, Cerrado, Mata Atlântica and Pantanal) (Fraga \& Paula-Souza, 2015). On the other hand, M. angulata occurs only in Central America, Amazonian regions of South America and Central Brazil (Mato Grosso and Mato Grosso do Sul). Further investigation is needed to confirm if either the L. cymulosa or $D$. dentatus is the $M$. angulata host.

Ray et al. (2009) studied the competition for mates in M. robiniae (Forster, 1771). According to them, the male of this species uses many tactics for separating mated pairs. These violent disputes usually entail the amputation of appendices (Larsson, 2010). Ray et al. (2009) noted that choice of tactic was not related by the size of challengers neither by relative size of defenders. Briefly, Ray et al. (2009) comments: "larger challengers were most successful when prying or pushing, while smaller challengers were most successful when biting and kicking. By using different tactics, relatively small males were as adept as larger males at displacing rivals."

Ginzel \& Hanks (2003) concluded in their experiments that some species of cerambycids attempted to mate with females only after contacting them with their antennae. Among the species used, are two of Megacyllene genus [M. caryae (Gahan, 1908) and M. robiniae]. Ginzel et al. (2006) were able to identify one of the main components of the pheromones involved in the mate recognition in M. caryae.

Megacyllene angulata presents a similar behavior to the other species of the genus. The occurrence of such behavior provides subsidies for future in situ or ex situ observations and the verification of the chemical components present in the involved pheromones.

\section{ACKNOWLEDGEMENTS}

F.E.L.N. is grateful for the grant 2017/15283-9, São Paulo Research Foundation (FAPESP). A.M.S.N and D.M.M.M. thank the Instituto Nacional de Pesquisas da Amazônia (INPA) for research support. A.M.S.N. thanks particularly the support for the Capes-INPA research grant (Process: 88887.312051/2018-00). D.M.M.M. thanks particularly the support for the CNPq research grant (Process: 141878/2018-5). We are also grateful to Jonas Alves de Oliveira for the essential help and logistical support in field collection in Tefé and MsC. Magno Luís Vásquez Pilco, a researcher from the Biodiversity Research Program - PPBio/INPA, for identifying the plants.

\section{REFERENCES}

Fraga, C.N. \& Paula-Souza, J. 2015. Dilleniaceae in Lista de Espécies da Flora do Brasil. Jardim Botânico do Rio de Janeiro. Available at: http://floradobrasil. jbri.gov.br/jabot/floradobrasil/FB7357. Access in: 13/05/2019.

Ginzel, M.D. \& Hanks, L.M. 2003. Contact pheromones as mate recognition cues of four species of longhorned beetles (Coleoptera: Cerambycidae). Journal of Insect Behavior, 16: 181-187.

Ginzel, M.D.; Moreira, J.A.; Ray, A.M.; Millar, J.G. \& Hanks, L.M. 2006. (Z)-9Nonacosene-Major component of the contact sex pheromone of the beetle Megacyllene caryae. Journal of Chemical Ecology, 32: 435-451.

Hanks, L.M. 1999. Influence of the larval host plant on reproductive strategies of cerambycid beetles. Annual Review of Entomology, 44: 483-505.

Hanks, L.M. \& Wang, Q. 2017. Reproductive biology of cerambycids. In: Wang, Q. (Ed.) Cerambycidae of the World: Biology and Pest management. Boca Raton, Fl., CRC Press. p. 133-159.

Hanks, L.M.; Millar, J.G. \& Paine, T.D. 1996. Mating behavior of the eucalyptus longhorned borer (Coleoptera: Cerambycidae) and the adaptive significance of long "horns". Journal of Insect Behavior, 9(3): 383-394.

Larsson, F.K. 2010. Limb amputation by male Neotropical longhorn beetles during competition for females. Biota Neotropica, 10: 339-341.

Lingafelter, S.W.; Wappes, J.E. \& Ledezma, A.J. 2017. Photographic Guide to Longhorned Beetles of Bolivia. Washington D.C., Smithsonian Institution Scholarly Press. $260 \mathrm{pp}$.

Martins, U.R. \& Galileo, M.H.M. 2011. Subfamília Cerambycinae, Tribo Clytini Mulsant, 1839. In: Martins, U.R. (Ed.). Cerambycidae Sul-Americanos (Coleoptera) Taxonomia. São Paulo, Sociedade Brasileira de Entomologia. v. 12, p. 1-264.

Monné, M.A. 2001. Catalogue of the Neotropical Cerambycidae (Coleoptera) with known host plant - Part I: Subfamily Cerambycinae, Tribes Achrysonini to Elaphidiini. Publicações Avulsas do Museu Nacional, 88: 1-108.

Monné, M.A. 2018. Catalogue of the Cerambycidae (Coleoptera) of the neotropical region. Part I. Subfamily Cerambycinae. Available at: http:// cerambyxcat.com. Access in: 15/03/2019.

Ray, A.M.; Ginzel, M.D. \& Hanks, L.M. 2009. Male Megacyllene robiniae (Coleoptera: Cerambycidae) use multiple tactics when aggressively competing for mates. Environmental Entomology, 38(2): 425-432.

Tavakilian, G. \& Chevillotte, H. 2018. Titan: base de données internationale sur les Cerambycidae ou Longicornes. Available at: http://titan.gbif.fr/ index.html. Access in 10/02/2019. 